Article

\title{
Learning to Care, Learning to Be Affected: Two Public Spaces Designed to Counter Segregation
}

\author{
Ida Sandström \\ Department of Architecture and Built Environment, Lund University, 22100 Lund, Sweden; \\ E-Mail: ida.sandstrom@arkitektur.Ith.se
}

Submitted: 29 May 2020 | Accepted: 18 September 2020 | Published: 12 November 2020

\begin{abstract}
In response to social fragmentation and segregation, public space is increasingly conceived of as an instrument for fostering openness towards differences. Drawing on two recent public spaces-Superkilen in Copenhagen, Denmark, and Jubileumsparken in Gothenburg, Sweden-this article explores the ethical potential of two different design approaches to the sharing of public space-designing for an ethics of care and an ethics of affect. Although different in terms of design, Superkilen and Jubileumsparken are both influenced by artistic approaches in their aspiration to make people connect emotionally to the space. In their design, the two spaces display contrasting approaches to community: Jubileumsparken invites its visitors to join shared projects, suggesting that community is a potential that may be realised through processes of collective care-it is a space in which we learn to care when working together. Superkilen works in an almost opposite way, confronting its visitors with transnational formations, diversity and designed fragmentation leading to situations, or moments, in which we may learn to be affected by distant atmospheres and faraway people and places. When studied together, the two spaces display a range of everyday situations in which the personal, or even the intimate, may be experienced along with the deeply collective-be it through shared work or the exposure to those or that different from you. It is finally argued that this palette of everyday situations, in which we learn to care and learn to be affected, holds an ethical potential of expanding the notion of community beyond sameness and unity, as seen in Superkilen and Jubileumsparken.
\end{abstract}

\section{Keywords}

affect; care; community; Denmark; public space; segregation; Sweden; urban design; urban diversity

\section{Issue}

This article is part of the issue "Built Environment, Ethics and Everyday Life" edited by Mattias Kärrholm (Lund University, Sweden) and Sandra Kopljar (Lund University, Sweden).

(C) 2020 by the author; licensee Cogitatio (Lisbon, Portugal). This article is licensed under a Creative Commons Attribution 4.0 International License (CC BY).

\section{Introduction: Can Public Spaces Promote a More Coherent Society?}

In Scandinavia today, public space has moved to the centre of discussions on how to achieve the socially sustainable city. In response to growing segregation and social fragmentation, public space is increasingly conceptualized as an instrument for fostering openness towards differences (Mukhtar-Landgren, 2012). In a Swedish planning context, it was suggested almost 15 years ago that a segregated public space is more dangerous than segregating housing (Svensson, 2006)-and the idea that inclusive public spaces can promote a more cohesive society has guided municipal planning in Sweden since then. It is in public space that we see those who are different from us - this is where acceptance, or perhaps even an interest in difference, is to be fostered. The ethical potential of this suggestion will be discussed concerning actual makings of public space, and in light of current developments, but first, something ought to be said about the planning culture from which these spaces have originated.

Parallel to the increased trust in public space, urban professionals in Scandinavia have lately experienced a growing distrust in the traditional planning paradigm and its ability to produce equal and neutral public spaces (discussed in a European context by Sohn, Kousoulas, \& Bruyns, 2015) and more generally speaking, to con- 
tribute to a coherent society (Grange, 2014, 2017). A devaluation of conventional planning has opened the door to more experimental modes of working with urban design and planning; temporary interventions, eventbased forms of participation, collaborative or opensource configurations. Characteristic of such practices is the exploratory and curating role taken on by architects and planners (Runting, 2018) and correspondingly, an increased interest in design solutions deriving from particular groups and interests (Sandström, 2019). The idea that heterogeneity may be promoted by making particular interests influential points to questions of design and power. Which uses, spatial practices and groups should be encouraged-why some and not the others? Mukhtar-Landgren (2012, p. 148) points to a fundamental dilemma: How can urban design and planning embrace differences and urban diversity without losing their responsibility to represent everyone, i.e., a general public? Adding to that concern, a related question of community can be added: What kinds of communities are created or supported in design processes deriving from interests articulated by particular groups? The inclination to foreground particular interests in public space may well increase diversity at a city level by strengthening the presence of underrepresented groups, but on the ground, it will still build on sameness as the prerequisite for community, if we understand sameness as "either established against, or productive of, but in any case presupposes difference" (Pettersson, 2015, p. 10). The notion of difference and sameness opens up to many interpretations; concerning the spaces of this study, it is particularly relevant to stay attentive to how people share space with those who are different from them in terms of life situations and background.

Critiques of sameness as a pre-requisite for community have been articulated from within political science (Pettersson, 2015), sociology (Brighenti, 2014) and philosophy (Nancy, 1991, 2000), but less within the field of architecture and planning. The conception of community as an apolitical constellation of people who 'belong together' seems harder to dispatch in relation to urban planning. Concurrent societal changes such as the use of communications technologies and increased mobility make it increasingly difficult to say who goes where, and therefore also to say who belongs together. Seeing the difficulties of categorisation and the persistent risk of segregation and social fragmentation, there is a need to think about public space in relation to more open forms of community; how can urban planning and design promote a sense of community between people who differ in terms of culture, origin and lifestyle? In the following sections, I seek to answers this question through the study of two recent makings of public place: Jubileumsparken in Gothenburg, Sweden and Superkilen in Copenhagen, Denmark-both made with a stated ambition to reflect and promote diversity, and to counter segregation. Despite ideological similarities, the two spaces are fundamentally different in their take on community-as I will show in the following sections. The discussion is consequently centred on several design approaches that seem particularly influential for developing what is from here on discussed as an ethics of care (Jubileumsparken) and an ethics of affect (Superkilen). With the attempt to further understand communities based on care and affect, I will by the end of this article discuss Superkilen and Jubileumsparken in the light of the recent corona pandemic.

\section{Learning to Care, Jubileumsparken}

Jubileumsparken is a temporary park established in a centrally located harbour area in Gothenburg, Sweden. It is a pre-run for a new city park that will be ready for Gothenburg's 400-year celebration as a city in 2021, for which several strategically located new public spaces have been suggested to make the city more attractive and less segregated. Jubileumsparken has been developed in phases, taking time into great consideration in the development scheme. An extensive temporaryuse strategy, centred on the notion of co-creation, was applied to establish the park gradually. The on-site work started in 2013 when fences were taken down and basic infrastructure was put in place, and in 2019 the park included several features such as a roller derby rink, an area for urban gardening, two swimming pools, a beach and what has become the most iconic feature of the park: a public sauna. The process is guided by the idea that public value can emerge before the actual construction phase. In line with that, the public has been invited to join in the making of the park through several workshops, in which the future uses of the park were tested on a 1:1 scale (see Figures 1 and 2). Focus is on public participation, co-creation and various forms of civic engagement and care. Several design approaches appear to have been particularly influential in developing what I discuss as an ethics of care at Jubileumsparken. The following three design strategies will be addressed below: building lasting attachments, entering civil-public-partnerships, and curating controversies.

\subsection{Building Lasting Attachments}

Although some spaces at Jubileumsparken stay open for everyone to use at all times of the day, other spaces and activities must be booked in advance. Some spaces made and designed for specific groups or uses even require membership for full access. One example is the roller derby rink, where only members of a team are allowed at certain times of the week (see Figure 3 ). The urban garden is another example of the same strategy-one needs to be a member of Jubileumsodlarna, the gardening community, to be allowed to do any gardening in the area. On Facebook, the members of Jubileumsodlarna have an online community in which they discuss a wide range of issues stretching from the future plans for the park to the risk of being visited by produce thieves dur- 


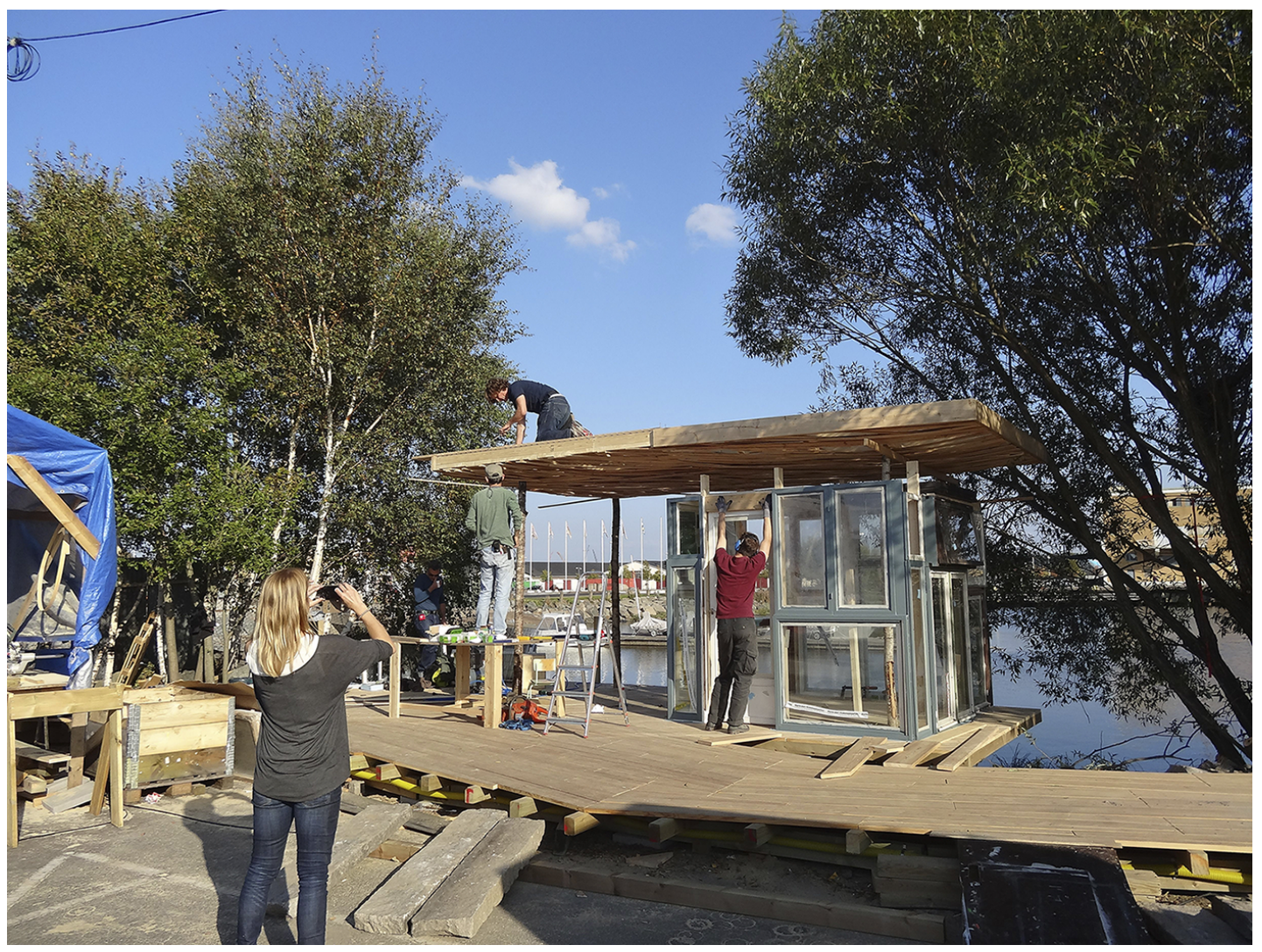

Figure 1. Building a small library pavilion during a public workshop at Jubileumsparken (2014). Photo: Ida Sandström.

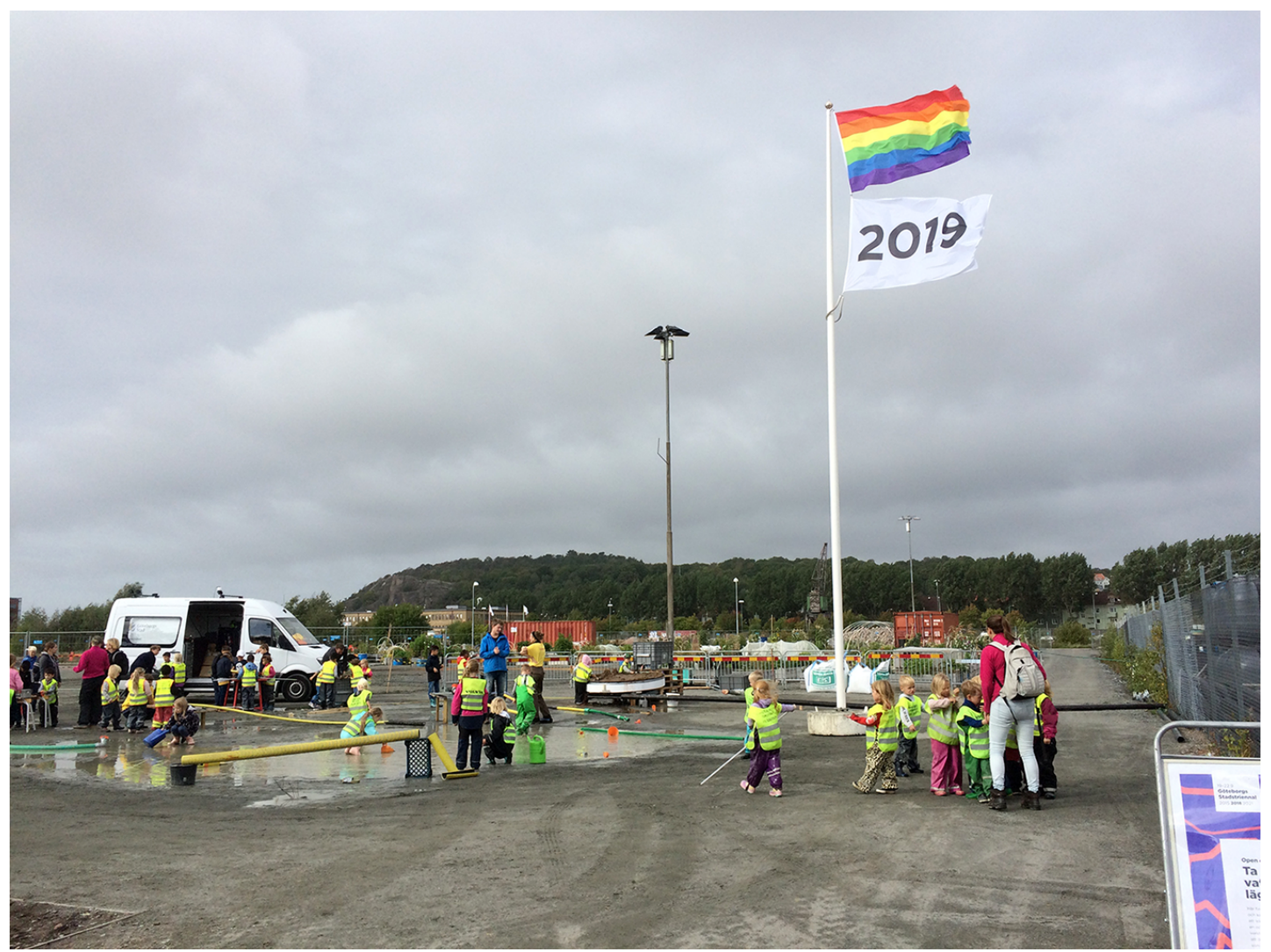

Figure 2. Open call with children: Investigating what a future playground could be in scale 1:1 (2018). Photo: Ida Sandström. 


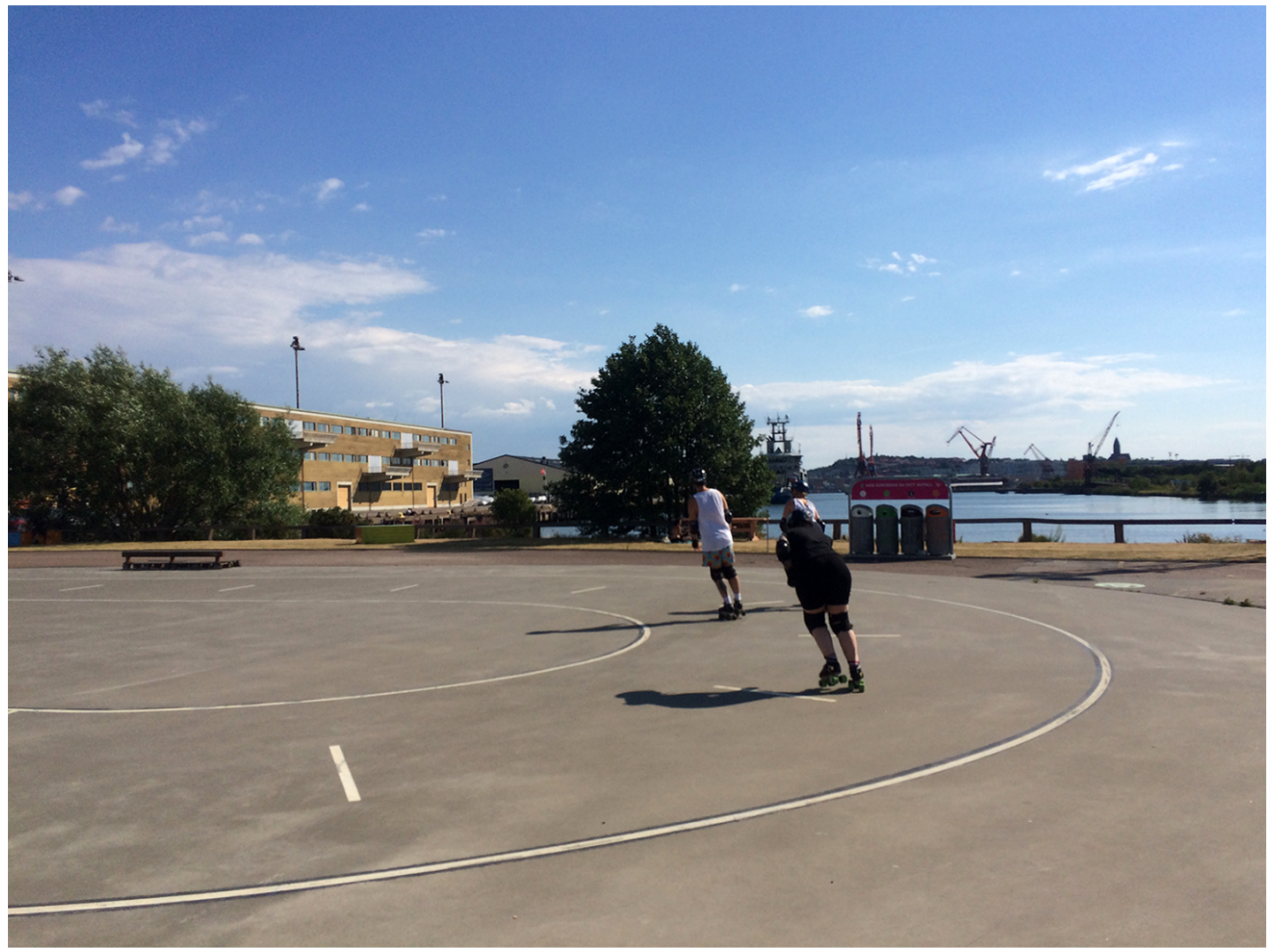

Figure 3. Roller derby training at Jubileumsparken (2018). Photo: Ida Sandström.

ing the night. This online community-page is also where they share gardening advice and arrange watering when someone is away. The high level of care for the space and for the community as such undoubtedly depends on continuity over time (a base for solidarity and growing friendships) and also to some extent on predictability. Jubileumsparken's design is based on the idea that attachment to the space grows with time, but also on the idea that specific interest (such as the wish for an urban garden) must be heard early in the process to make the space relevant for a large number of people. It is seen as particularly important to hear socially vulnerable or underrepresented groups. The city has accordingly entered into dialogue with particular groups with the belief that urban diversity depends on the intentional foregrounding of less visible or resourceful groups. This belief has resulted in the number of workshops directed to specific groups such as women, children and asylum seekers-and some features at the park are made as a direct response to the demands made in such dialogues. One example is a flexible greenhouse structure located by the beach: This was made in response to the need for a sheltered space for eating, socialising and keeping strollers, expressed by a group of Muslim women who participated in a dialogue on bathing culture. The rollerderby rink and the inclusive sailing school are two other examples of spaces made in direct response to specific demands and requirements from groups connected to those activities.

\subsection{Entering Civil-Public-Partnerships}

Jubileumsparken's project leader describes Jubileumsparken as a place where the visitor is received by 'hearts and hands' (interview 20 November 2015), i.e., by people deeply engaged in the space. This strategy, to populate the park, is especially evident in the maintenance plan for the park. Jubileumsparken is part of a 'civilpublic-partnership' with an NGO, Passalen, who was commissioned to operate the park in 2015. With the one exception of emptying the waste bins, they have since been responsible for the maintenance of the whole park, including running the public sauna and directing the inclusive sailing and swimming education. Each summer, Passalen employs young people from all over the city as 'park hosts,' a role that is central to the maintenance plan-they embody the idea of populating the park with 'hearts and hands.' The park hosts are recruited to represent different districts in Gothenburg, but also to be different in terms of interests, ethnicity and body abilities. Being a park host is as much education as it is employment, one learns everything needed for the position on the job-for instance, one does not need to be able to sail before being employed as a sailing instructor, adequate training is provided by Passalen and the city administration. This is a way to make the recruitment of park hosts more inclusive in terms of socio-economic background. As the construct with park hosts shows, Jubileumsparken is a space that develops both physical and social capacities. 


\subsection{Curating Controversies}

The colour scheme at Jubileumsparken is bright with a distinctive do-it-yourself aesthetic. Spray-painted slogans known from activist circles such as 'The Queer Revolution is Close,' 'Another World is Possible,' and other politically charged messages are to be read on the ground. It is interesting to know that the writing, which could have been an undesirable element in another place, was here initiated within the project and painted by an invited artist and architecture collective during an event hosted by the city. And this is not the only way political messages are curated in the park: In August 2015, Jubileumsparken was subject to what appears to have been a political act of dissent. The project leader of Jubileumsparken explains what happened:

We had an incident this summer with paint in the pool and graffiti on a house. 'Stop gentrification' it said in black letters. We let the text remain throughout the whole season and had a dialogue about it, talked to our visitors about it. It was all good in a way. (Interview 20 November 2015)

So the action itself, the writing on the wall and the paint in the pool were not initiated from within the project administration, but from the moment it was discovered it was curated as an asset. It was used as a 'conversationpiece' and a starting point for a dialogue on the longterm development of the park-a way to bring public engagement triggered by the controversy into the project-and to further support Jubileumsparken as a site of care.

\subsection{Developing an Ethics of Care}

What is the ethical potential of a space characterised by engagement and care? The notion of 'care' has been explored extensively concerning architectural practice in recent years (Fitz, Krasny, \& Wien, 2019; Fraser, 2016; Tronto, 2015). The feminist scholar Maria Puig de la Bellacasa discusses the difference between being affected by something and caring about something. She writes:

We can think of the difference between affirming, 'I am concerned' and 'I care.' The first denotes worry and thoughtfulness about an issue as well as, though not necessarily, the fact of belonging to the collective of those concerned, 'affected' by it; the second adds a strong sense of attachment and commitment to something. Moreover the quality of 'care' is to be more easily turned into a verb: to care. One can make oneself concerned, but to 'care' contains a notion of doing that concern lacks. (Puig de la Bellacasa, 2017, p. 42)

As Puig de la Bellacasa points out, the word care is twofold as it addresses the affectionate connection to the space on the one hand, and the labour of caretaking on the other hand. Jubileumsparken invites people to connect with the spaces in this dual sense, asking its visitors to care about the space, but also to take care of the space by investing work into it-following the belief that the level of commitment will increase proportionally with the time and work invested in a space. Jubileumsparken presents itself as a site shaped by love and affection on the one hand, and by labour and work on the other hand as seen for instance in the urban gardening. To think of care as a co-producer of public space is also to acknowledge space as continuously created through both affective and practical efforts. It must however be remembered that care is always a situated practice; care-taking might be a delight in one situation, but feel heavy and oppressive in another setting. In relation to urban planning, it is therefore wise to revisit the topic of care in the particular situation and to stay interested in the inclusions and exclusions created in particular and site-specific processes defined by care. If community is staged as a collective project, as seen in the example of the urban gardening at Jubileumsparken, who will join in and who will not? Invitations to participate will speak to some people, but not to others; this is why care, understood as an emotional and practical undertaking, cannot be communicated as the only way to belong to a space and its community. Keeping that in mind I will now turn to Superkilen, a public space that displays an almost antagonistic strategy to Jubileumsparken's belief in care as the prime driver in the making of community.

\section{Learning to be Affected: Superkilen}

Superkilen is a public space in central Copenhagen, Denmark. It was financed by the Danish association Realdania and the City of Copenhagen. The park consists of three connecting parts-each with a different colour-indicating, it seems, different atmospheres and intensities. Since it opened in 2012 (see Figure 4), the space has gained a lot of attention for its design strategy to fill the space with a large number of everyday objects and street furniture from around the world. The design plays with relationships between far-flung places; each one of the 108 objects at Superkilen is also a fragment of another place (see Figures 5 and 6 ). The objects invite the visitor to engage in a wide range of activities. Whereas some objects relate to specific activities such as boxing, square dancing, playing chess and barbequing, others are designed for more general activities like resting, walking and playing. Because of its collection of foreign objects, its colourful and unconventional design, Superkilen has recurrently been compared to a world exposition. The discussion in the following sections is centred on three design strategies that appear to have been particularly influential when establishing Superkilen as a space in which we may learn to be affected by people and situations far away from our selves: Making difference the shared experience, 


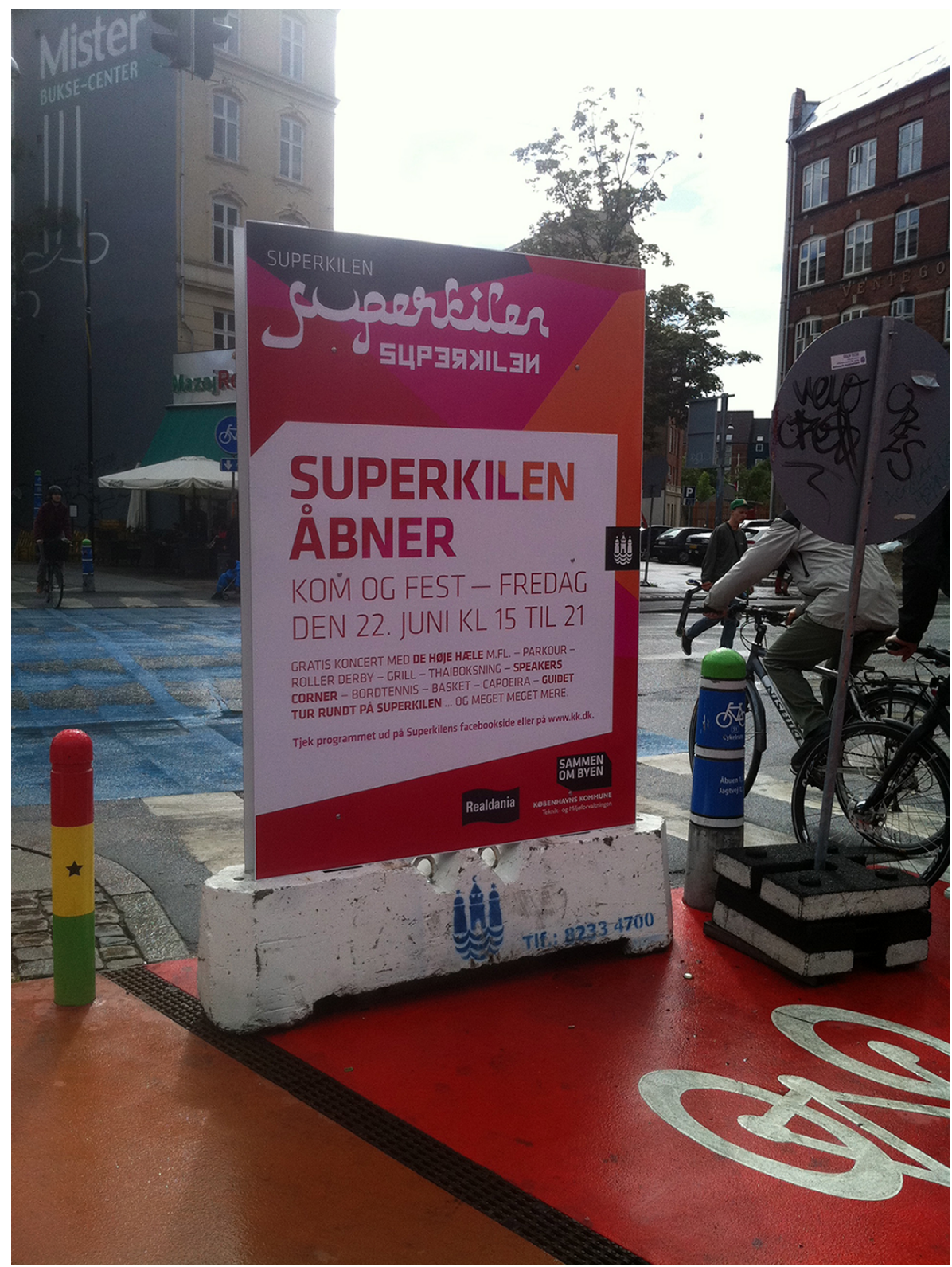

Figure 4. 'Superkilen is opening: Come and party': Billboard announcing the opening of Superkilen, June 2012. Photo: Ida Sandström.

highlighting the universal and designing for transversal connections.

\subsection{Making Difference the Shared Experience}

The particular atmosphere at Superkilen is created through several hyper-present objects from around the globe. Whereas many objects come with a story of eviction and migration, some relate more to tourism and adventures. One example of the later is the bull from Spain, chosen by two retired Danish ladies who had been travelling to Spain since their youth. Still, a visitor at Superkilen can not walk far without being exposed to politically charged objects: soil from Palestine, Kurdish benches and an elephant slide from Pripyat, an abandoned town close to Chernobyl (see Figure 6). The expo- sure of objects with strong political connotations creates a certain level of provocation at the site. Realdania's representative explains the strategy in the following way:

If you have soil from Palestine or a manhole from Israel, will some people spit on it. Yeah, maybe, but still, of course, we hope nobody would do this. The idea is that everybody respects that we are coexisting together. (As cited in Steiner, 2013, p. 70)

Situations that could potentially stir up anger are instead trusted to build respect for difference, and the message is clear: At Superkilen, we do not only coexist, but we coexist together. The space comes with the hopeful idea that the experience of difference can become a shared experience in itself. 


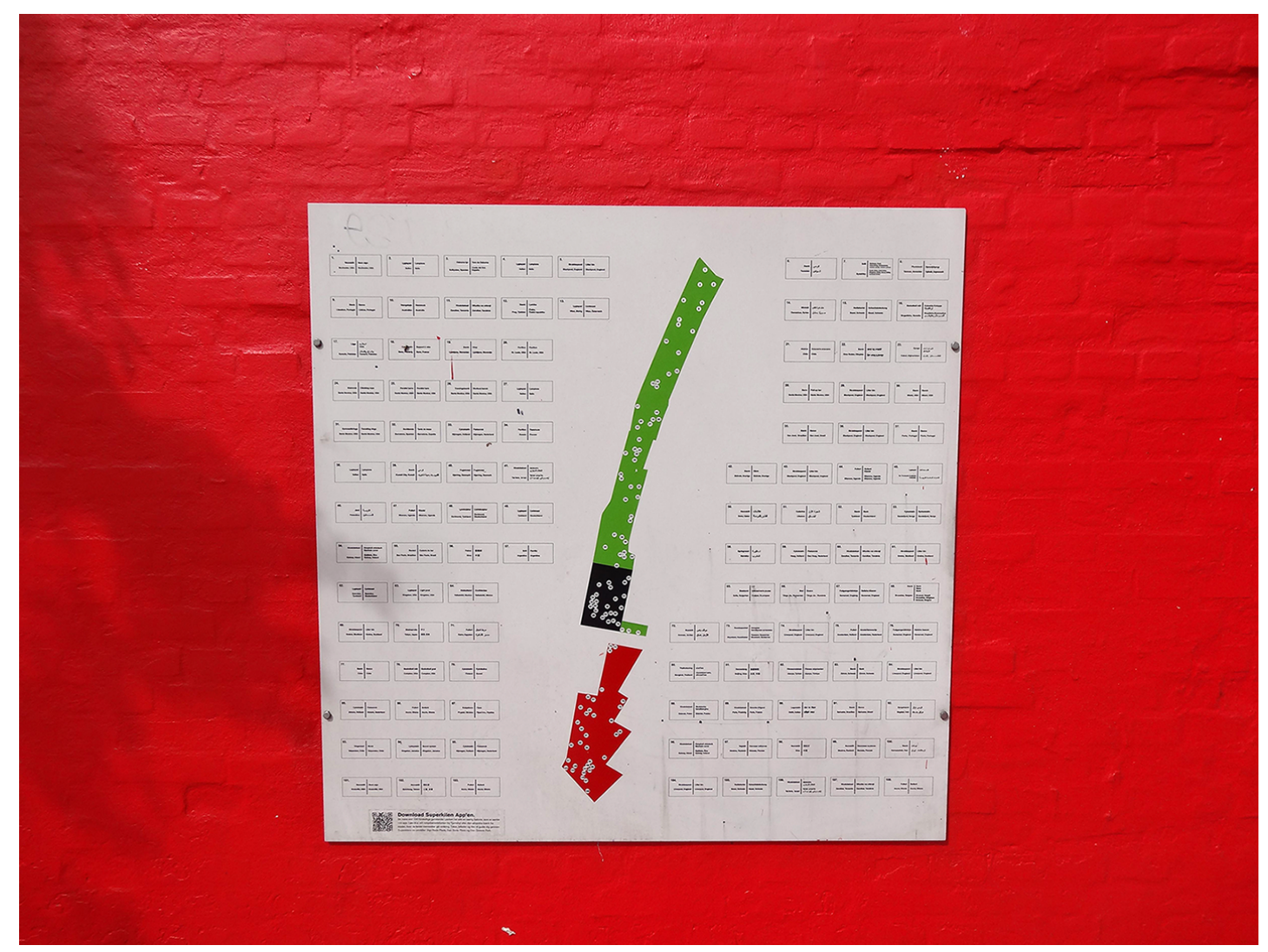

Figure 5. Sign on the wall showing the location of the 108 objects at Superkilen. All object are named in Danish and their original language. Photo: Ida Sandström.

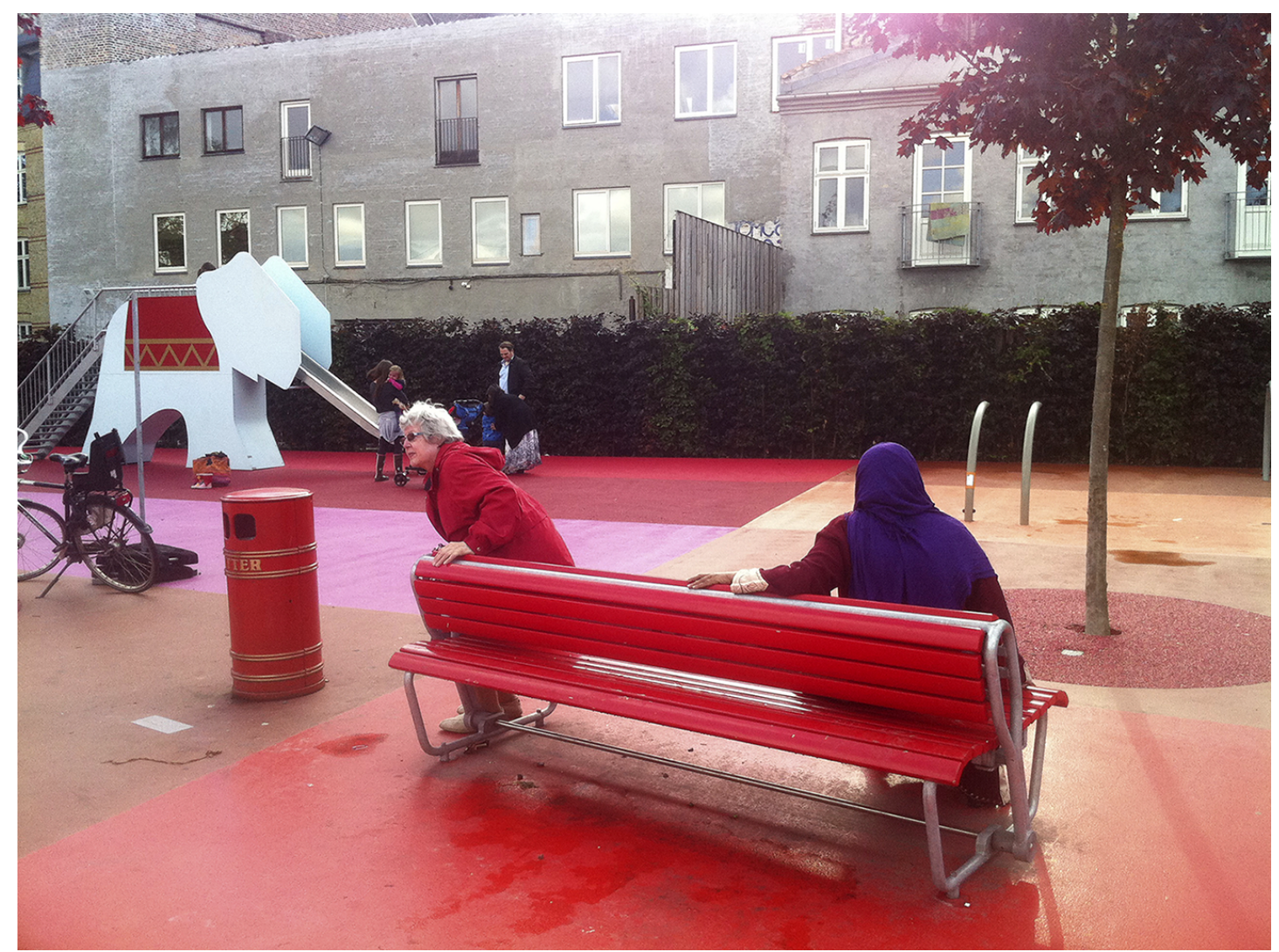

Figure 6. Objects at Superkilen: A British litterbin, a bench from Zurich and an elephant slide from Pripyat, the abandoned town for workers at Chernobyl (2015). Photo: Ida Sandström. 
Whereas Jubileumsparken is a public space made to encourage long-lasting relationships and attachments to the site, most social interactions at Superkilen happen through brief encounters. People unknown to each other would typically share a bench for a short period, before walking off in different directions. Occasionally, brief conversations occur, but more often, strangers remain strangers. The confrontational quality of the space is intensified when a wide selection of people, interests and habits of using public space are exposed to each other. While there were several sports clubs involved in the making of Superkilen at an early stage, no established clubs use the facilities today. The fact that nothing can be booked or reserved in advance creates a situation where one will never know whether a space or facility is available at a certain time. The space and its facilities are accessible to many, but it is hard, if not impossible, to use the space for pre-arranged or organised activities. No one is entitled to a certain space or object; this is why the sharing of space becomes an on-going negotiation on the ground.

\subsection{Highlighting the Universal}

The design of Superkilen is fragmentary and scattered: Objects are 'thrown out' with the hope that they will create some reactions or even better connections between people. The space becomes an invitation to connect with sentiments of playfulness and beauty, but also with personal stories of loss, longing and exile. Let me illustrate this condition in a brief detour to a harbour regeneration project I was part of some years ago. On one occasion, artists invited to comment on the development of the area wrote questions on walls and buildings by the harbour. The questions, written with huge letters, were personal and intimate: 'What have you lost?,' 'Do you care?,' 'Are you feeling lonely?'-using the second-person singular 'you' rather than a more general third person. At Superkilen, a similar technique has been used. By placing an extensive number of objects relating to different human experiences side by side, the visitor is exposed to shared basic sentiments of human life such as loss, loneliness, and affection. Through that site-design, a "minimal/ maximal we is formed-minimal in the sense that it does not build on any shared identities, interests or concerns, and maximal in the sense that it is incalculable in its inclusion of all subjects related to the site" (Sandström, 2019, p. 263). Superkilen may be experienced precisely in this double binding of singular beings sensing the universal human condition across differences.

\subsection{Designing for Transversal Connections}

The fragmentary design of Superkilen makes it a space that foregrounds not only the objects as such, but also the distances between them. The French philosopher Jean-Luc Nancy (1991) uses the French word 'partager' to address the spacing of community. The word partager means both to share and to divide, and for Nancy, this is exactly what community does. It is the space between us that makes it possible to move towards each otherto connect. A consequence of this thinking is that difference is necessary for community. This move, placing the drift towards differentiation at the heart of community is the radical move of Superkilen. It is a space that allows its visitor to experience the particular atmosphere that emerges when one is affected or touched by those different to oneself-suggesting that the space that we cross when we reach for something or someone exterior to ourselves is an essential part of community.

For example: In 2011, the artist group SUPERFLEX travelled to Palestine in the company of two young women with ancestries in Palestine. They travelled with a mission-to reach the site of the former village of the women's ancestors, and bring back an object from there to Copenhagen. After a long and emotional search, the women found what they believe to be traces of their relatives' houses in the wide, undulating landscape. The journey from Copenhagen to Palestine and back was documented and can be seen in four films uploaded on Superkilen's homepage. The last film shows the process of transporting a large plastic trunk with soil from the Palestinian highlands to its final destination, a much smaller hill at Superkilen. Some years later, I encountered a group of international students having a lunch picnic on this very hill where the soil is placed. As it turned out, they were unaware of its presence. Once the students became aware of the Palestinian soil on which they had laid their picnic blanket, they reacted with distress, shame and regret (it was almost as if they had been caught disrespecting the grave of someone). The transformation of the atmosphere was abrupt, and the students started moving their things to get away from the Palestinian soil. How can this sudden shift of atmosphere be understood concerning ethics and affect? I suggest that the students' collective reaction to the sudden discovery of Palestinian soil triggered not only awkwardness, but also a degree of connection, or even, in the broadest sense of the word, of community.

\subsection{Developing an Ethics of Affect}

The term affect gained influence with Deleuze and Guattari's reading of Spinoza in the 1980s (1988/2013). Despite more recent attempts to discuss affect concerning cities and cultural production (see, for instance, Thrift, 2008), the question on how to use it in architecture and planning remains somewhat open, as pointed out by Kopljar (2016). Affect is, on the one hand, discussed as the ability to affect, i.e., one object's ability to have an impact on another object, and on the other hand, as a capacity associated with feelings, i.e., with the trigger of affections. Affect theory (Massumi, 2002; Shouse, 2005 ) tends to distinguish between these two aspects of affect. However, a space like Superkilen points to the difficulty in discussing affect and affections (emotions) as 
two distinctive and separate capacities. Superkilen is a space that plays with the very idea that an object or an event in one place can affect objects and events in other places, but it is also a space made to affect its visitors emotionally - and the two processes, to affect and to be affected, are here inherently interconnected.

Drawing on this paired understanding of affect, what is the ethical potential of a space characterised by the exposure of difference, a space in which we may learn to be affected? Superkilen's endeavour to make difference the shared experience relates to Nancy's idea of community as a space of radical exposure. A space where connection must be understood not in terms of what we have in common, but that we are in common, and where the singularity of every being is exposed to the singularity of others. Community seen in this way is not based on any shared values, identities or practices, and it cannot be achieved through any work and effort. The strategy, which was discussed earlier, of creating community by exposing highly personal yet universal conditions resonates with Nancy's (2000) suggestion that we are always singular, but always longing for connection, hence also always related and plural. As human beings, we are constantly reaching out to each other, repeatedly attempting to connect and repeatedly failing at sustaining such connections over time. The potential of community is therefore situated in the enactment of what has been described as "momentary, exceptional acts of coming together" (Anderson, 2017, p. 593). Let me return to the situation with the picnic on the hill at Superkilen with that in mind-the students' affectionate reaction to the origin of the soil can be seen as a transient experience of "the moment, the point, or the event of beingin-common" of which Nancy speaks (1991, pp. xxix-xl). Drawing on observations from Superkilen, I suggest that the condition of 'being-in-common' that Nancy speaks of (1991, pp. xxix-xl) may be experienced in exactly such passing moments of transversal connections. Nancy speaks of community as a circumstance in which we "learn to be affected" (Anderson, 2009, p. 77) by distant or vague atmospheres, and by people and places far away from us. The soil at Superkilen is not only soil but also a pledge to connect to the destiny of Palestine and its people. We catch sight of the fact that we are separate, but always relational to each other-and this, I suggest, is the ethical potential of Superkilen.

\section{Spaces of Collective Care, Spaces of Being-in-Common}

As I have attempted to show, Jubileumsparken is a space that presents itself as a space in need of relentless attention and care. In this way, it promotes relational attachment to the space as such. Compared to many public spaces, Jubileumsparken does not strive for the durable and robust. Instead, it operates with fragile social processes and materials that call for continuous maintenance and care. Many features in the park, such as the pools, the sauna, and the urban garden, could not be sustained without processes of extensive maintenance and care. The production of relational attachment through practical everyday work is particularly evident in the construction surrounding the 'park hosts' who care for the park in the double sense of affection and practical work. My study suggests moreover that it is not only professionals who care for Jubileumsparken. Care is also performed by its regular visitors, as seen among the urban gardeners, who help each other with watering and other practical tasks. To sum up, I have so far addressed Jubileumsparken as a space of care and commitment, characterised by its highly curated processes of social interactions. I have also discussed how attachment to the space is encouraged through specific operative models such as the maintenance model based on a civil-public partnership and an extensive number of public workshops.

Superkilen on the other hand is addressed in this article as a space that confronts the visitor with several issues but does not ask for any practical, hands-on engagement. At Superkilen, there are no plants to water, no sauna sessions or swimming lessons to join, and no workshops to attend. In contrast to Jubileumsparken, Superkilen does not represent itself as a site of care. Here, the visitor is not demanded-or invited-to relate to the space, or to other people in the space, through any practical work or long-term commitment. Instead, the visitor is confronted with a large number of objects and people different from herself. A setting that may trigger transient connections-i.e., moments in which the visitor is touched by people and places that are foreign to her. It is also in these moments that one might catch sight of the human condition of being singularplural, i.e., of being separate, yet always in relation to others. Separation becomes the prerequisite for connection. Drawing on Nancy, we can reach a certain kind of togetherness if we acknowledge that the "being of fundamental difference" is the primary condition that all beings share (1991, pp. 27-28). If we think of community as the result of people coming together around shared projects, as seen at Jubileumsparken, it will be hard to catch sight of any community formations at Superkilen. To even distinguish community at Superkilen, we will have to give up on unity as the precondition for connection.

The difference between Superkilen and Jubileumsparken's approach to community comes through in how the two spaces are represented in social media. In a mapping I made from 987 Instagram posts from each space, several interesting differences surfaced. Although this is by no means a complete representation of the two spaces (one can think of many trivial activities that would seldom, if ever, be shared on social media) they are interesting as a collectively produced record of our attention. Whereas a large part of the pictures from Jubileumsparken show activities that demand some kind of group affiliation, such as swimming-, bikingand sailing-for all, the urban garden, and roller derby 
training-such pictures are almost completely missing at Superkilen. Superkilen on the other hand has an extensive number of photos in which people are posing for the camera, relating to the space itself, and to its objects. Also, there are more posts showing events, food and parties at Jubileumsparken. The greatest difference is, however, to be seen in the number of posts relating to the actual making of each space. Whereas only four posts relate to the making of Superkilen, there are 97 posts depicting the making of Jubileumsparken (see Figure 7). This includes posts relating to the actual building and planting of the park, the construction of buildings such as the sauna and the library pavilion (see Figure 1) and the planning processes. Again Jubileumsparken comes forward as a space designed to support collective processes of care, and Superkilen as a space designed for, and characterised by, exposure, disruptions and affecta space of being-in-common.

\section{Conclusions}

Seeing the two spaces together, they outline two different ways to think about community in public space. While Jubileumsparken builds primarily on the idea that communities are produced continuously through shared projects, Superkilen points in the other direction, advocating a kind of community that is not based on what we have in common, but the fact that we are in common. At the heart of the matter is whether we think of community as something that happens when we come together around a shared project (an ethics of care), or rather as a kind of transversal connection that we may experience when we sense a shared human condition (an ethics of affect). Although they differ on an ontological level, I argue that both strategies point to interesting possibilities to think about community without unity. A space characterised by an ethics of care advocates a non-essentialist take on community by acknowledging the many overlapping and fluid community formations that may take place at a site, leaving the individual free to move in-between them and engage in several communities at the same time. It has also been suggested in this article that the act of coming together around a project can attract a diverse group of people that would not usually meet and interact. A space characterised by an ethics of affect is, however, more radical in how it places difference in the heart of community, suggesting that exposure may trigger a kind of momentary connection between people who are far away from each other in every sense of the word.

To deepen the discussion on care and affect as two entries to an inclusive understanding of community, I would like to turn to the current moment in which this article is written. In the Spring of 2020, the Covid-19 pandemic has caused an immense disturbance to singular lives around the globe. It is a peculiar time to write and think about the assets of public space. Travels, celebrations and get-togethers are being cancelled, and a combination of fear and legal restrictions has made people return to their homes, leaving squares and streets in many cities quiet and empty. Tragedy and despair are immense, but the pandemic has not only brought devas-

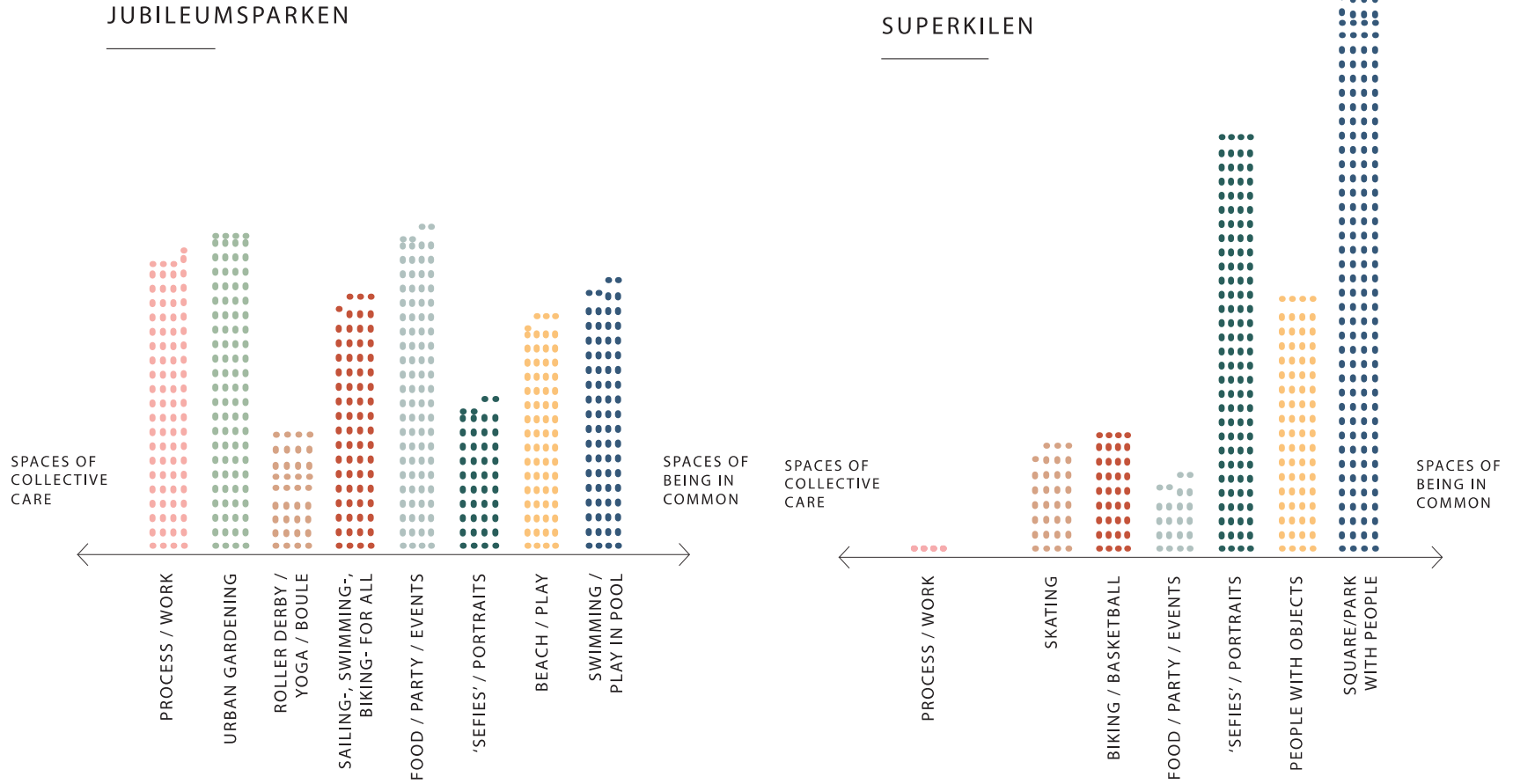

Figure 7. Instagram posts from Jubileumsparken and Superkilen categorised on a scale from spaces of collective care (ethics of care) to spaces of being-in-common (ethics of affect). Note: Each dot represents one Instagram post. Source: Ida Sandström. 
tation, but also a rare chance to rearticulate the ethical dimensions of living together in cities-perhaps even a renewed potential for community? During the pandemic, new initiatives to keep up the social and technical infrastructures of the city arise; people organise themselves in order to support sick or elderly neighbours, to help quarantined children with their homework, and to set up home factories to produce materials for local hospitals. Drawing on the discussions from Jubileumsparken, we see an increased level of engagement and care, involving people who did not consider themselves part of the same community before the crisis, in shared efforts. Parallel to the potential of connection across difference, the pandemic has also to some extent rendered segregation more visible; some groups are more affected than others, a bias that seems to shadow pre-existing power dynamics. The virus is in that sense capable of producing its own communities of affected that (tragically) overlaps with socio-economic vulnerable groups. In order to further progress in the discussion on community, we must not sidestep the more ruthless sides to the pandemic. When things were at its worse, ice rinks, churches and other public buildings in cities around Europe were turned into mortuaries, leaving their inhabitants exposed to mortality and human loss in a most literal sense. Returning to Nancy's suggestion that community is a moment in which we are touched by a shared human destiny-this extreme exposure may also carry a potential for a renewed sense of community. In a situation where small and seemingly innocent actions (such as going to work or throwing a party) may threaten the bare existence of others, we will inevitably catch sight of the connectedness of all people. A shared human destiny is no longer an abstraction, but the position from which we have to act on a day-to-day basis. Covid-19 has not only taken away the possibility to travel freely, but also the option to act as a sovereign self, and this is a situation that pushes us towards the kind of condition that Nancy talks of, where community does not depend on what we have in common in terms of interests and preferences, but the fact that we are in common-unescapably connected as humans.

It has been suggested, concerning other catastrophes, that the longing for real connection stays an unrealised potential in ordinary life, but comes alive in the extraordinary situation of a crisis (Solnit, 2009). The two spaces that I have studied suggest that design can play a similar role by pushing us into unexpected situations in which we may open up to strangers. I have attempted to show how those two spaces have established an ethics of care (Jubileumsparken) and an ethics of affect (Superkilen) through several distinct design strategies. I have also shown how the different ethical standpoints are deployed in the mundane use of the two spaces. The community gardening at Jubileumsparken and the picnic on Palestinian soil at Superkilen are two examples of everyday situations in which one may learn to care (Jubileumsparken) and learn to be affected (Superkilen).
I suggest, concluding, that the demand for public spaces that can counteract segregation and social fragmentation calls for an intensified interest in the mundane use of public space, and consequently in the urban design that enables it. Urban design may, if used wisely, support everyday situations that hold the ethical potential of expanding the notion of community beyond sameness and unity, as seen at Superkilen and Jubileumsparken.

\section{Acknowledgments}

The article is part of a project on public space and practices of sharing. It has been financed by the City of Helsingborg, Lund University and the Chamber of Commerce in Helsingborg. Some of the research of this article was conducted within the doctoral project "Towards a minor urbanism, thinking community without unity in recent makings of public space" (Sandström, 2019). The author would like to thank the project leader of Jubileumsparken for the interview in Gothenburg, 20 November 2015.

\section{Conflict of Interests}

The author declares no conflict of interests.

\section{References}

Anderson, B. (2009). Affective atmospheres. Emotion, Space and Society, 2(2), 77-81.

Anderson, B. (2017). Hope and micropolitics. Environment and Planning D: Society and Space, 35(4), 593-595.

Brighenti, A. M. (2014). The ambiguous multiplicities: Materials, episteme and politics of cluttered social formations. Basingstoke: Palgrave Macmillan.

Deleuze, G., \& Guattari, F. (2013). A thousand plateaus: Capitalism and schizophrenia. London: Bloomsbury Academic. (Original work published 1988)

Fitz, A., Krasny, E., \& Wien, A. (Eds.). (2019). Critical care: Architecture and urbanism for a broken planet. Boston, MA: MIT Press.

Fraser, N. (2016). Contradictions of capital and care. New Left Review, 100, 100-116.

Grange, K. (2014). In search of radical democracy: The ideological character of current political advocacies for culture change in planning. Environment and Planning A: Economy and Space, 46(11), 2670-2685.

Grange, K. (2017). Planners: A silenced profession? The politicisation of planning and the need for fearless speech. Planning Theory, 16(3), 275-295.

Kopljar, S. (2016). How to think about a place not yet: Studies of affordance and site-based methods for the exploration of design professionals' expectations in urban development processes. Lund: Faculty of Engineering of Lund University.

Massumi, B. (2002). Parables for the virtual: Movement, affect, sensation. Durham, NC: Duke University Press. 
Mukhtar-Landgren, D. (2012). Planering för framsteg och gemenskap: Om den kommunala utvecklingsplanerings idémässiga förutsättningar [Planning for progress and community: The discursive preconditions for municipal develpment planning] (Doctoral dissertation). University of Lund, Lund, Sweden.

Nancy, J.-L. (1991). The inoperative community. Minneapolis, MN: University of Minnesota Press.

Nancy, J.-L. (2000). Being singular plural. Stanford, CA: Stanford University Press.

Pettersson, J. (2015). Incalculable community (Doctoral dissertation). University of Lund, Lund, Sweden.

Puig de la Bellacasa, M. P. (2017). Matter of care, speculative ethics in more than human worlds. Minneapolis, MN: University of Minnesota Press.

Runting, H. (2018). Architectures of the unbuilt environment (Doctoral dissertation). Royal Institute of Technology, Stockholm, Sweden.

Sandström, I. (2019). Towards a minor urbanism: Thinking community without unity in recent makings of public space (Doctoral dissertation). University of Lund, Lund, Sweden.
Shouse, E. (2005). Feeling, emotion, affect. M/C Journal, 8(6). Retrieved from http://journal.media-culture. org.au/0512/03-shouse.php

Sohn, H., Kousoulas, S., \& Bruyns, G. (Eds.). (2015). Introduction: Commoning as differentiated publicness. Footprint, Delft Architectural Theory Journal, 9(1), 1-8.

Solnit, R. (2009). A paradise built in hell: The extraordinary communities that arise in disaster. London: Penguin.

Steiner, B. (2013). Superkilen. Stockholm: Arvinius + Orfeus.

Svensson, P. (2006). Vision Norra Sorgenfri: Inför omvandling och planarbete [Vision Norra Sorgenfri: Before transformation and planning work]. Malmö: Malmö stad.

Thrift, N. (2008). Spatialities of feeling. In N. Thrift (Ed.), Non-representational theory: Space, politics, affect (pp. 171-195). London and New York, NY: Routledge.

Tronto, J. C. (2015). Who cares? How to reshape a democratic politics. Ithaca, NY: Cornell University Press.

\section{About the Author}

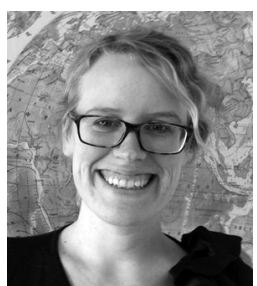

Ida Sandström is an Architect. She holds a PhD in Architecture from the School of Architecture at Lund University. Her thesis is titled Towards a Minor Urbanism: Thinking Community without Unity in Recent Makings of Public Space (2019). Bringing together social and material aspects of urban life, her work outlines several ways to think and build more inclusive urban spaces. Ida has previously been working in urban planning and design, primarily in Sweden. 